\title{
Interpreting local critical orientations of structural weakness in relation to stress and dilatancy in rock slopes
}

\author{
J.V. Smith School of Civil, Environmental and Chemical Engineering, RMIT University, Australia
}

\begin{abstract}
The orientation of structural weaknesses, such as faults, joints, bedding and foliation, is a major influence on the stability of rock slopes. In the unloaded parts of benches, the critical orientation of structures is typically considered with respect to gravity. In the toe of each bench and the zone of rock behind the benches the critical orientations must be considered with respect to the local stress trajectory. In this zone the maximum principal compressive stress $\left(\sigma_{1}\right)$ is approximately parallel to the slope, in a two dimensional cross-section. This principal stress orientation approximates the inter-ramp slope angle for a series of benches with local steepening of the trajectory behind the lower part of each bench and local flattening behind the top part of each bench. The critical structures will be those with orientations favourable to slip with respect to the local $\sigma_{1}$ trajectory. The orientation of surfaces favourable to slip is also related to the friction angle and dilatancy of a material.

Materials which undergo no volume change during deformation typically slip on surfaces at $45^{\circ}$ to $\sigma_{1}$. Materials undergoing volume increase during deformation slip on surfaces at lower angles. This can be observed in conjugate pairs of structures where the slip occurs simultaneously on 'mirror image' structures. The angle between conjugate structures in rocks is typically around $60^{\circ}$, that is, each structure is inclined $30^{\circ}$ to $\sigma_{1}$. Experiments and field observations have shown that this angle decreases at lower confinement and increases at higher confinement.
\end{abstract}

Based on these relationships, a slope of $50^{\circ}$ would have $\sigma_{1}$ inclined at approximately $50^{\circ}$ (with local variations) and the conjugate critical structures would therefore be oriented at 20 and $80^{\circ}$ out of the slope. The low-angle structure would have a resolved shear displacement of sliding out of the slope. The high angle structure would have the opposite shear sense, that is, the block behind the slope moving down relative to the block nearer the slope face. Movement on the high-angle structures can appear to be a toppling failure. At the toe of the overall slope, where stresses are at their most concentrated, $\sigma_{1}$ will progressively flatten to horizontal as it goes under the pit floor. In the zone of greatest stress concentration, the $\sigma_{1}$ trajectory will approximate half the slope angle, depending on factors including the in situ stress ratio. At this location, $\sigma_{1}$ would be, for example, inclined at approximately $25^{\circ}$ and the conjugate critical structures would be oriented at approximately $5^{\circ}$ into the slope and $55^{\circ}$ out of the slope. Movement on the low angle structures can be upward into the pit and may appear to be heave in the pit floor. Movement on the high-angle structures can also appear to be heave in the pit floor.

Rock slopes which contain structural weakness oriented in one or both of the local critical orientations will undergo plastic yield at a lower threshold than other rock masses. The susceptibility of structures to this effect can be assessed from a stereograph using the down-dip line of the slope as a surrogate for the maximum principal compressive stress direction and half this angle for the overall slope toe. Numerical modelling of confining stress and consideration of the friction angle and dilatancy of the rock mass will also assist in identifying the sensitivity of a rock mass to local critical structural orientations. 


\section{$1 \quad$ Introduction}

\section{$1.1 \quad$ Localisation of deformation}

Field observations, laboratory and numerical studies show that rock masses and particulate materials in general, commonly deform by the formation of localised deformations, often termed shear bands (Rudnicki and Rice, 1975; Bésuelle et al., 2000). The orientation of shear bands is affected by confining stress, friction and dilatancy. Where friction and dilatancy are zero, shear bands form at $45^{\circ}$ to the maximum principal compressive stress $\left(\sigma_{1}\right)$. Therefore conjugate pairs of such shear bands would form at $90^{\circ}$ to each other. As friction and dilatancy increase shear bands form at decreasing angles to $\sigma_{1}$. Rudnicki and Rice (1975) investigated the orientation of shear band formation in elastic-plastic material with respect to a range of parametres. Recent distinct element modelling of shear band orientation shows similar relationships (Schopfer and Childs, 2013). Data on the relationship between shear band orientation and dilatancy in these studies are illustrated in Figure 1. The relationship between shear band orientation and friction from Rudnicki and Rice (1975) is illustrated in Figure 2 and follows the general trend expected from Mohr-Coulomb behaviour (Yu, 2006).

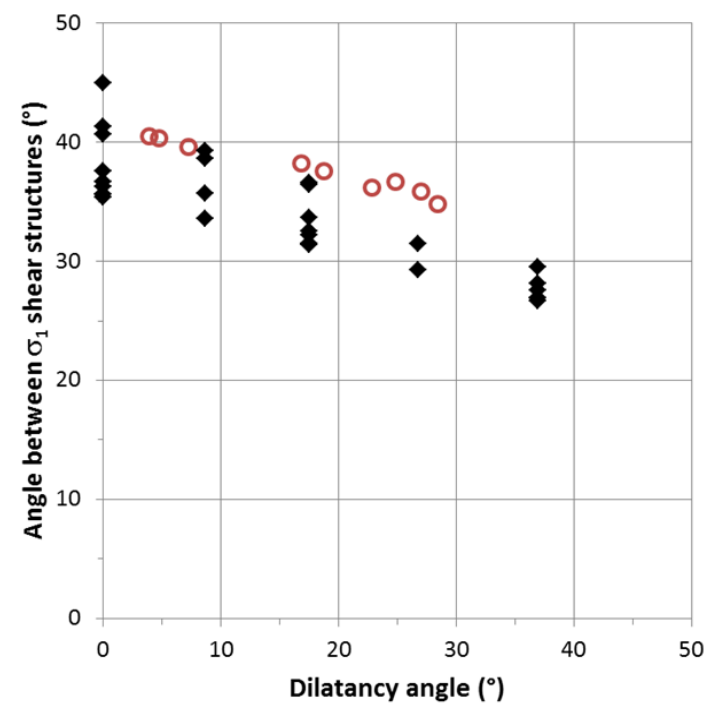

Figure 1 Relationship of the angle between conjugate shear bands and dilatancy from elastoplastic numerical modelling (diamonds: Rudnicki and Rice, 1975; circles: Schopfer and Childs, 2013) 


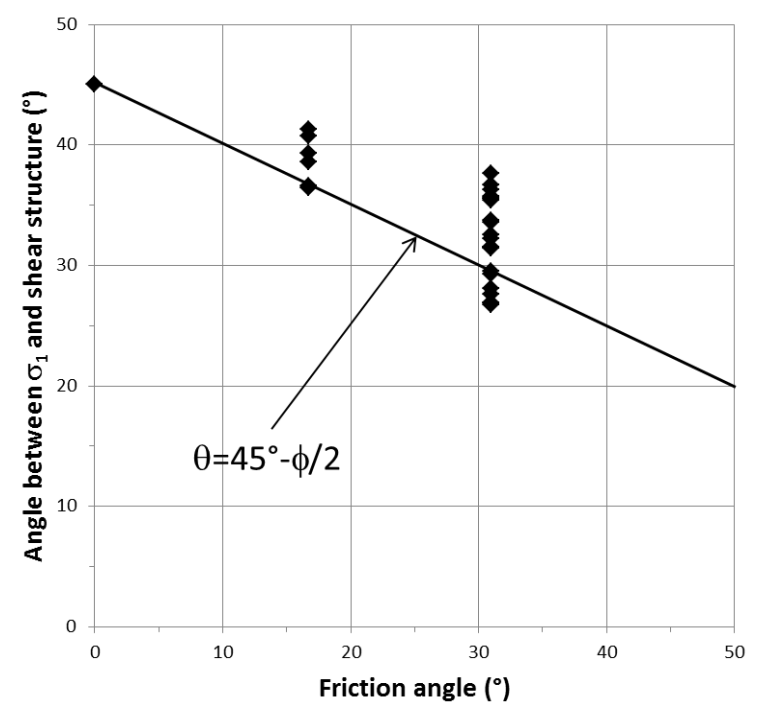

Figure 2 Relationship of the angle between conjugate shear bands and the friction angle (data from Rudnicki and Rice, 1975). $\theta$ = angle on $y$-axis, $\phi=$ friction angle

The development of shearing within rock masses can be understood as a form of plastic deformation. In plastic deformation there are lines of compatible shear flow known as slip lines (Yu, 2006). The slip lines occur in pairs which are symmetrical about the principal compressive stress direction $\left(\sigma_{1}\right)$. Slip lines are also referred to as characteristics as these directions are solutions to the compatibility equations of flow.

For a material with cohesion but no friction, the slip lines are orthogonal to each other, that is, at $45^{\circ}$ to $\sigma_{1}$. For a frictional material the slip lines form at a lower angle to $\sigma_{1}$. According to plasticity theory as applied to Mohr-Coulomb material behaviour, the orientation of the slip line relative to $\sigma_{1}$ is decreased by a factor equal to half the friction angle (Yu, 2006).

In relation to rock masses, slip lines are the directions in which shear zone localisation can be expected to occur. In addition, if a zone of weakness coincides with a slip line direction then the onset of shear displacement may occur at an earlier stage of deformation than would otherwise be expected. Most published studies focus on the localised initiation of new shear structures within a deforming rock mass (e.g. Rudnicki and Rice, 1975; Schopfer and Childs, 2013) but less attention has been paid to the role of pre-existing weakness. The 'orientation susceptibility' of pre-existing weak zones will depend on their frictional and dilational properties.

Durney (1979) and Smith and Durney (1992) linked shear zone orientation and dilatancy with strain compatibility and the strain characteristics, otherwise known as plastic slip lines (Figure 3). To maintain strain compatibility the strain along the shear zone must be equal to the strain outside, but parallel to, the shear zone. The strain being considered can be the total finite strain or any other increment of strain. The analysis is readily applied to small increments of strain using infinitesimal strain theory to address the localisation of shear strain during an increment of deformation. Once initiated the deformation will be focussed in one or both of the shear zones and the zones themselves will undergo relatively minor rotation during the further accumulation of finite strain. 


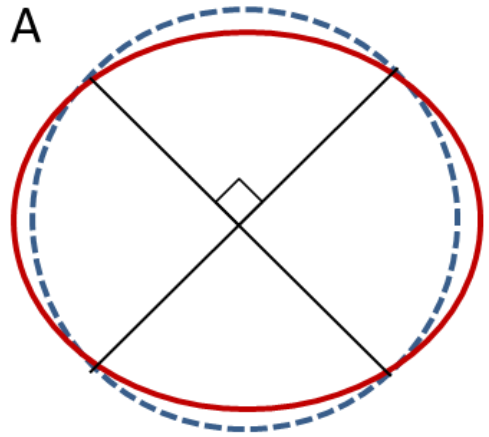

$\Delta \mathrm{V}=0$

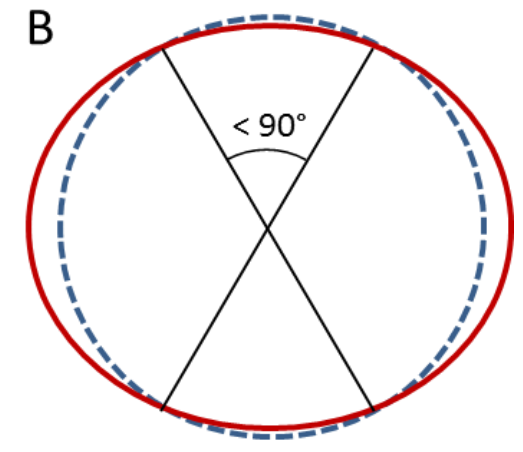

$\Delta \mathrm{V}>0$

\section{$>$ Slip Lines, Characteristics}

Figure 3 Shearing surfaces develop along the characteristic lines of the infinitesimal strain field. The lines are located at the intersection of the undeformed (dashed circle) and deformed strain ellipse (red ellipse). The angle between shear surfaces and the principal stress directions and principal infinitesimal strain axes is related to the volume change $(\Delta V)$ of the strain field (after Smith and Durney, 1992)

The critical structures will be those with orientations favourable to slip with respect to the local $\sigma_{1}$ trajectory. The orientation of surfaces favourable to slip is also related to the friction angle and dilatancy of a material. Materials which undergo no volume change during deformation typically slip on surfaces at $45^{\circ}$ to $\sigma_{1}$. Materials which undergo volume increase during deformation slip on surfaces at lower angles.

This phenomenon is best observed in conjugate pairs of structures where the slip occurs simultaneously on 'mirror image' structures. The angle between conjugate shear structures in rocks is typically around $60^{\circ}$, with $\sigma_{1}$ as the bisector. Each conjugate shear structure is inclined at $30^{\circ}$ to $\sigma_{1}$. Experiments and field observations have shown that the conjugate angle decreases at lower confinement and increases at higher confinement.

\subsection{Dilatancy}

The importance of developing a clear, theoretical and practical understanding of dilatancy in rock masses has been outlined by Alejano and Alonso (2005). In their review they note that, Detournay (1986) recognised that dilatancy is expected to decrease with increasing plastic strain (damage) and they proposed an exponential decay function for dilatancy.

Hoek and Brown (1997) recommended a range of values for dilatancy angle from one-quarter of the friction angle (at peak strength) for good rock to zero for poor quality rock. If we recognise that strain of the rock mass will decrease its quality, it is clear that a decreasing dilatancy angle approach should have general applicability. According to Brown (2008, p. 14), previous studies 'suggest that the post-peak dilatancy angles for rocks and rock masses are unlikely to be constraints but to decrease with plastic strain following yield'. The decrease in dilatancy in post-peak deformation can be attributed to strain localisation in that any dilatancy occurring within the shear zones represents a small quantity in comparison to the bulk deformation.

Cundall et al. (2003, p. 23) developed a numerical modelling approach in which the instantaneous dilation angle varies and is typically 'large dilation at low confining stresses and small or zero dilation at large confining stresses, as the failure condition is approached'. Yuan and Harrison (2004) reviewed rock mechanics test results to develop an empirical dilatancy index to measure the changing dilatancy behaviour at different confining pressures. 


\subsection{Critical orientations}

Rock masses can deform by movement on existing defects or by the formation of new fracture zones (e.g. Simmons and Simpson, 2006). This paper summarises how the relationships of orientation, friction and dilatancy of existing and newly formed shear structures can be related to inferred and modelled stress and strain in rock slopes.

One of the significant controls on the orientation of shear structures relative to principal stress trajectory is the dilation of the material occurring at the time the shear structures form and/or shear displacement occurs on the zone of weakness. Where pre-existing weaknesses are parallel to the plastic slip lines, localised shearing may occur at an earlier stage, that is, at a lower plastic strain than for the case of newly forming shear structures.

Rock masses typically require substantial dilation to occur before through-going shear structures can develop. Distributed plastic strain and therefore bulk dilatancy will reduce significantly after strain localisation occurs. Dilatancy may occur within the shear zones but this will make a small contribution to dilatancy of the entire rock mass. A negative feedback is present in that where a surface of weakness is close in orientation to the characteristic line further distributed dilation will not be required as deformation can proceed by displacement on the shear structures. This concept is also referred to as strain partitioning (e.g. Jones and Tanner, 1995).

\section{$2 \quad$ Stress trajectories in open pit slopes}

The stress trajectory is the local orientation of the principal stress, the maximum principal compressive stress $\sigma_{1}$ being of most interest. Stress trajectories, together with contoured stress magnitudes, provide a simple representation in two-dimensions. The orientation of a stress trajectory will depend on the remote stresses and any local disturbances to the stress field such as excavation geometry (Jaeger et al., 2007).

The redistribution of the orientation and magnitude of stress around open pits has been shown by field observation and modelling (e.g. Myrvang et al., 1993; Stacey et al., 2003). Franz et al. (2007, p. 635) observed that in distinct element numerical modelling 'slopes with a height of $500 \mathrm{~m}$ or more, the slope stress state causes structure slip to occur even if their dip angle is smaller than or equal to the structure friction angle, which is unexpected if general assumptions of limit equilibrium approaches are taken into consideration'.

Models of stress trajectories in benched slopes readily show that within the slope behind the de-stressed zone of the benches, the principal compressive stress directions are approximately parallel to the direction formed by joining the toe of each bench (Figure 4(a)). At the toe of the slope stress trajectories progressively rotate to be parallel with the floor of the pit (Figure 4(b)). Further away from the slope face the stress trajectory ( $\mathrm{s} 1$ ) will be determined by the relative magnitude ( $\mathrm{k}$ factor) of the remote stresses.

The orientation of structural weaknesses, such as faults, joints, bedding and foliation, is a major influence on the stability of rock slopes. In the unloaded parts of benches, the critical orientation of structures is typically considered with respect to gravity. In the toe of each bench and the zone of rock behind the benches the critical orientations must be considered with respect to the local stress trajectory. In this zone the maximum principal compressive stress $\left(\sigma_{1}\right)$ is approximately parallel to the slope, in a two dimensional cross-section. This principal stress orientation approximates the inter-ramp slope angle for a series of benches with local steepening behind the lower part of each bench and local flattening behind the top part of each bench (Figure 4). 

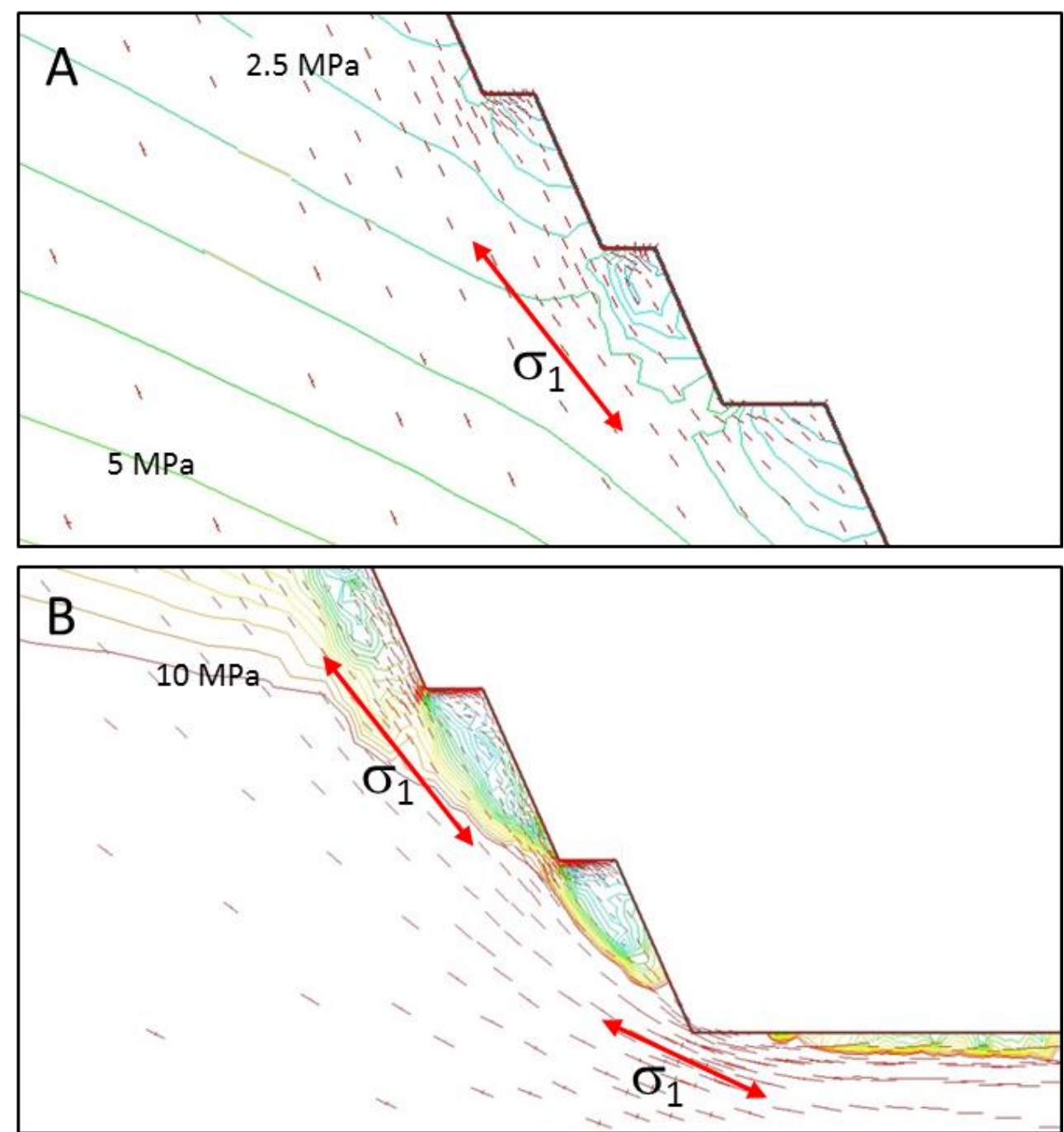

Figure 4 Detail from a larger finite element model $\left(\mathrm{Phase}^{2}\right)$ showing maximum principal compressive stress directions (bars) and contoured magnitudes at (a) $150 \mathrm{~m}$ below ground level; and (b) $500 \mathrm{~m}$ below ground level $(k=1)$. Stress trajectories are oriented approximately parallel to the inter-ramp angle and half the inter-ramp angle at the toe of the slope (double arrows). Batters are $30 \mathrm{~m}$ high

For any given stress trajectory it is possible to infer the potential for shearing on two surfaces with opposite shear sense (Figure 5). The typical angle between shear structures and $\sigma_{1}$ is variable but $30^{\circ} \pm 15^{\circ}$ is shown on Figure 6. 


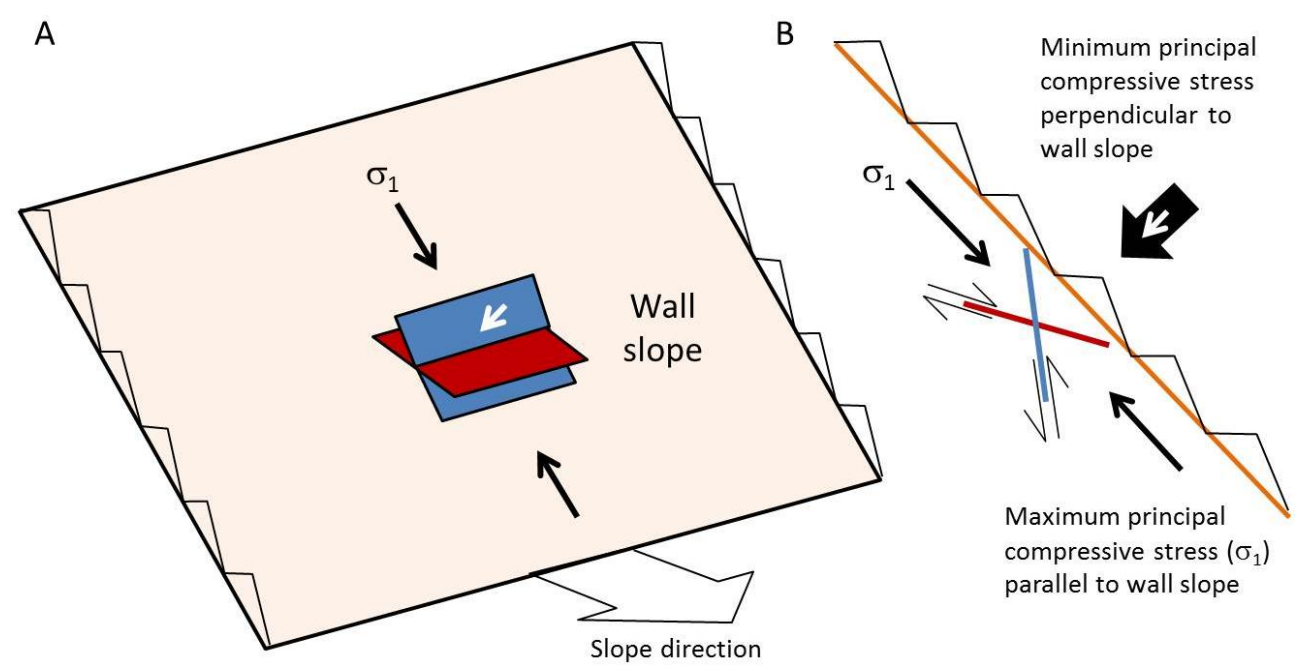

Figure 5 (a) $3 \mathrm{D}$ view of the geometric relationship between stress trajectory and potential shear structures; and

(b) Schematic cross-section

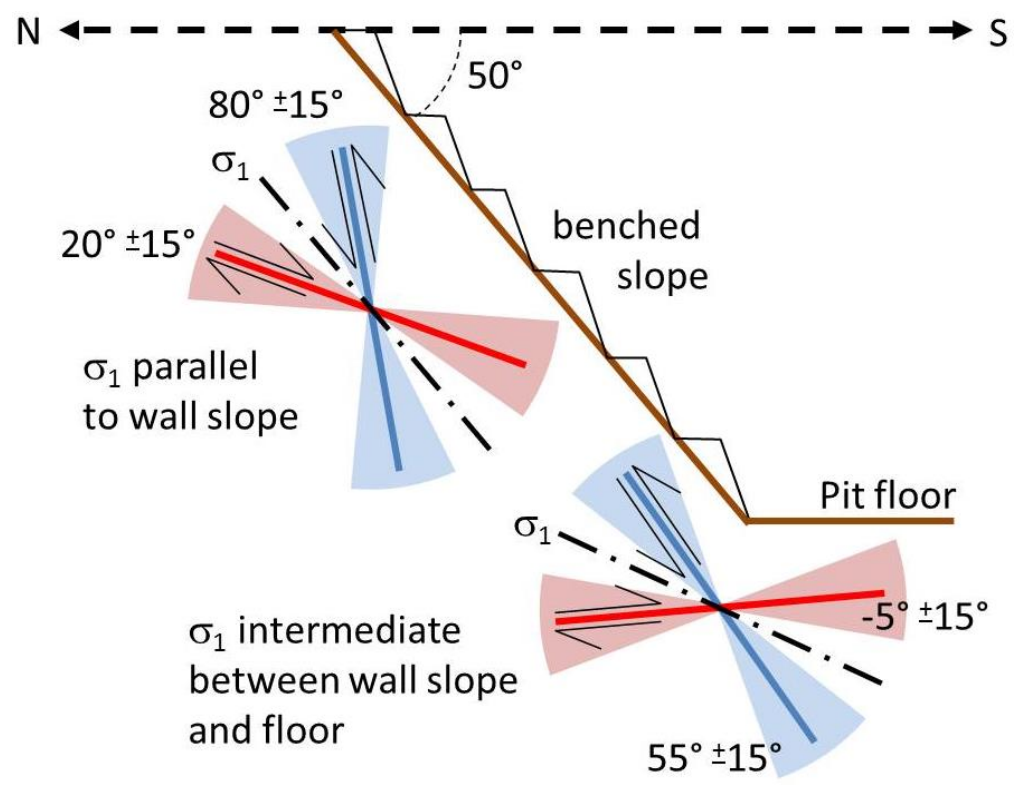

Figure 6 Schematic cross-section (looking east) of angular relationships illustrated in stereographs (Figure 8)

Figure 7 shows schematically the typical relationship between the angle of the structure relative to $\sigma_{1}$ and the friction angle. The actual angle and the range of angles varies with confining pressure, friction and dilatancy. The Mohr-Coulomb relationship is shown on Figure 7 as a guide but, the orientation of structures is expected to occur over a range depending on other variables. At low friction angle dilatancy is typically also low and the angle of structures relative to $\sigma_{1}$ is $45^{\circ}$. The variability on the left-hand side of the graph is shown as low because there is typically a low sensitivity to other variables such as confining pressure when friction angle is low. At high friction angles typical of rock masses, dilatancy is high but not necessarily linked directly with friction angle. Sensitivity to confining pressure is also high and the range of angles is consequently shown as being high on Figure 7. The trajectory of $\sigma_{1}$, determined by numerical modelling or inferred to be approximately slope-parallel, can be compared to the orientations of potential shear structures within the rock mass using the graph shown in Figure 7.

Note that angles greater than $45^{\circ}$ can occur when loss of volume occurs during deformation. This effect has been shown to occur at relatively high confining stresses in DEM studies (e.g. Schopfer and Childs, 2013) 
and is not considered of primary importance to the lower confinement conditions anticipated in open pit excavations.

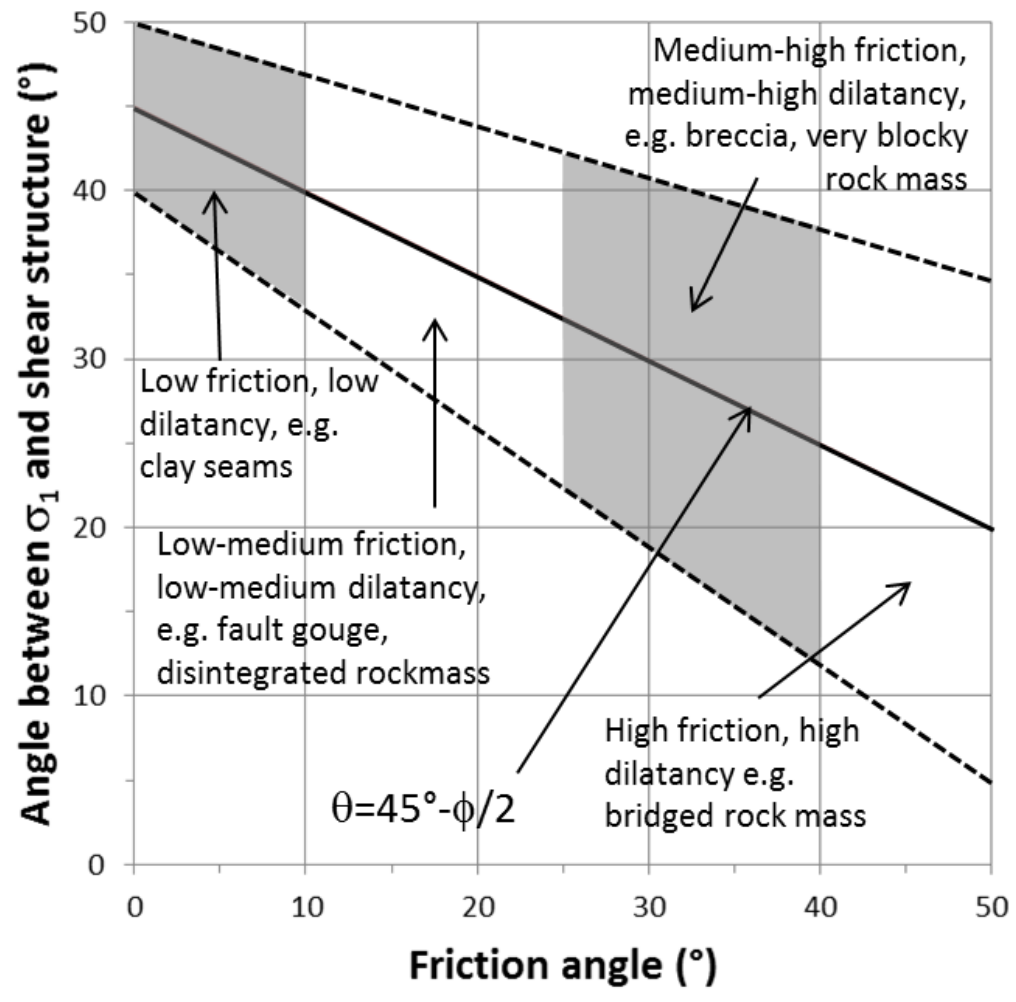

Figure 7 Graph of angle between $\sigma_{1}$ and structures related to friction angle

\section{Representation on stereographs}

The relationships of orientations of existing structures to the stress trajectory can be assessed on a stereograph using the down-dip line of the slope as a surrogate for the maximum principal compressive stress direction and half this angle for the overall slope toe. Within the slope behind the de-stressed zone of the benches stress directions are approximately parallel to the direction formed by joining the toe of each bench (Figure 8(a)). At the toe of the slope stress trajectories progressively rotate to be parallel with the floor of the pit (Figure $8(\mathrm{~b})$ ). The windows for identifying planes with potential for stress-induced slip are determined by plotting small circles around the inferred (or modelled) $\sigma_{1}$ direction. The small circles selected here are 45 and $75^{\circ}$ as these represent the range of poles to planes with angles between 45 and $15^{\circ}$ to $\sigma_{1}$. The intermediate value of $30^{\circ}$ midway between these values is a useful reference point. If a potential shear structure can be characterised as low-dilatancy or high-dilatancy, then the windows can be further refined toward the high and low angle, respectively. It is intended that the stereographic representation shown in Figure 8 be used as a screening tool for potential stress-induced instability in the much same way as gravity-induced kinematic feasibility is assessed using the conventional daylight window method.

The strike range is affected by intermediate stress and pit wall curvature. For moderately to steeply dipping structures the $\pm 20^{\circ}$ rule of thumb illustrated as dashed lines on Figure 8 may be appropriate (Hoek and Bray, 1981). For sub-horizontal to gently dipping structures the $\pm 20^{\circ}$ rule of thumb is unduly restrictive on the range of feasible orientations. Figure 8 shows an arbitrarily wider range of feasible structures for the shallowly dip to sub-horizontal sets of structures. 


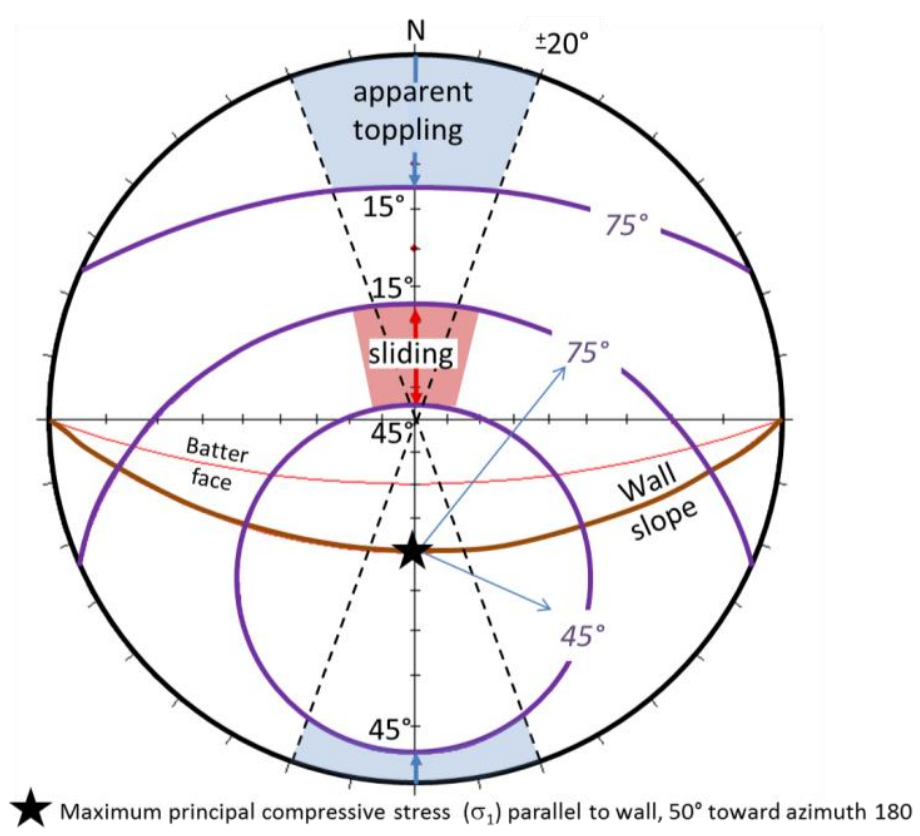

(a)

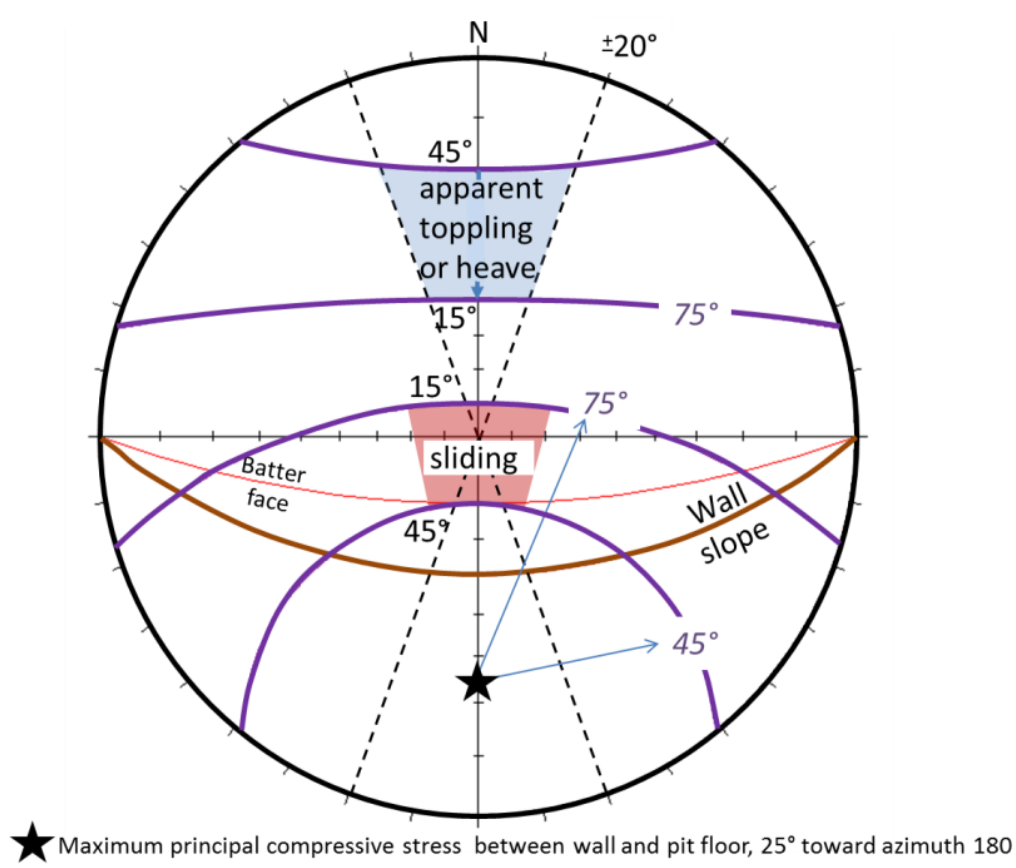

(b)

Figure 8 Equal angle stereographs showing the relationship between maximum principal compressive stress and shear surfaces; (a) maximum principal compressive stress trajectory parallel to the downslope direction on the pit slope; (b) maximum principal compressive stress trajectory is midway between the downslope direction on the pit slope and the horizontal floor. Numbers in italics are angles of bounding small circles

As an example, a small set of structural orientation data has been placed on the stereographic template (Figure 9). The data comprises one tight cluster dipping approximately $20^{\circ}$ toward the south and a broader population of structures with moderate to steep dips toward the north.

The four cases considered are: a wall sloping at $50^{\circ}$ toward the south (Figure 9(a)), the toe of the south-sloping wall (Figure 9(b)), a wall sloping at $50^{\circ}$ toward the north (Figure 9(c)) and the toe of the north-sloping wall (Figure 9(d)). 
For the south-sloping wall (Figure 9(a) and (b)), there is potential for stress-induced slip on structures dipping southward at approximately $20^{\circ}$. Note that this population would conventionally be considered to be stable as it is dipping at less than the typically expected friction angle of say 30 to $35^{\circ}$. Relatively, few structures are in the stress-induced apparent toppling window. At the toe of the slope both stress-induced slip windows have relatively few structures present.
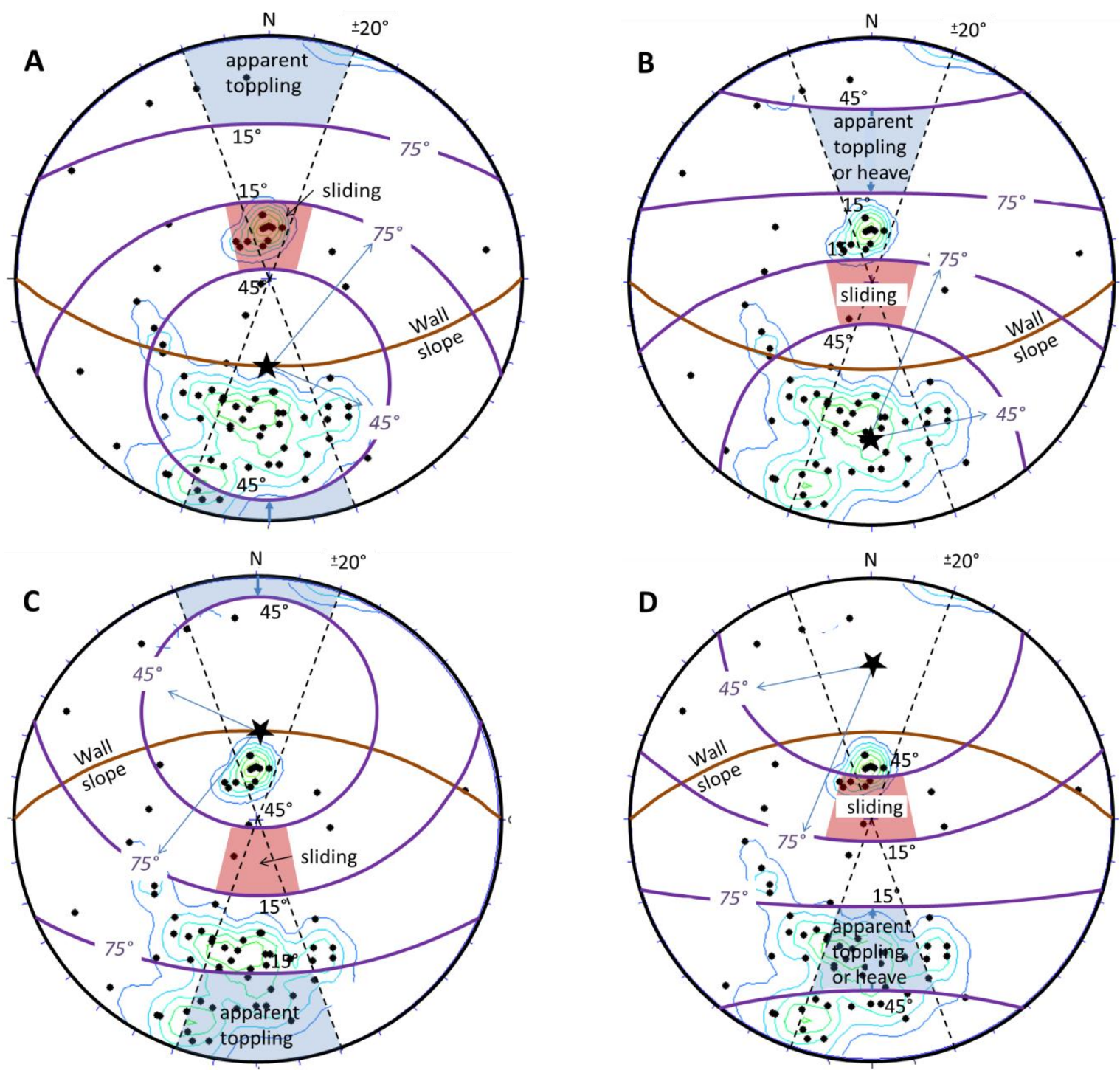

Figure 9 Equal angle stereographs showing the relationship between maximum principal compressive stress (star) and stress-induced sliding window templates for example data; (a) south-sloping wall $\left(5^{\circ}\right)$ with stress parallel to the wall; (b) toe of the southsloping wall where stress is oriented between the wall and the floor; (c) north-sloping wall $\left(50^{\circ}\right)$; and $(d)$ toe of north-sloping wall

For the north-sloping wall (Figure 9(c) and (d)), there are few structures in the low-angle sliding window but a moderate population of structures in the steep-dipping apparent toppling window. At the toe of the slope, the cluster of structures dipping into the wall at $20^{\circ}$ are at a critical orientation if they exhibit low friction, low dilatancy behaviour (i.e. at $45^{\circ}$ to $\sigma_{1}$ ). If high friction, high dilatancy behaviour is expected the susceptibility for stress-induced sliding on this set of structures at the toe is less. At the toe of the slope, there is a cluster of structures in the apparent toppling/heave window. The abundance of these feasible structures increases toward the low friction, low dilatancy part of the window (i.e. at $45^{\circ}$ to $\sigma_{1}$ ). 
Note that the $\sigma_{1}$ orientation will progressively change from parallel to the wall toward half way between the wall and the floor and decrease further under the floor. Therefore, intermediate stress orientations in addition to those shown in the template should also be considered.

\section{Discussion}

The stress-induced structural deformations discussed in this paper are expected to mainly occur in relatively steep and/or high pit walls where high stress levels occur. As an example, a pit slope of $50^{\circ}$ would have $\sigma_{1}$ inclined at approximately $50^{\circ}$ (with local variations) and if the dilatant rock mass formed shear zones at $30^{\circ}$ to $\sigma_{1}$ then shear structures would be oriented at 20 and $80^{\circ}$ out of the slope. The low-angle structure would have a resolved shear displacement of sliding out of the slope (Figure 10(a)). The high angle structure would have the opposite shear sense, that is, the block behind the slope moving down relative to the block nearer the slope face (Figure 10(b)). Movement on the high-angle structures can appear to be a toppling failure.

At the toe of the overall slope, where stresses are at their most concentrated, $\sigma_{1}$ will progressively flatten to horizontal as it goes under the pit floor. In the zone of greatest stress concentration, the $\sigma_{1}$ trajectory will approximate half the slope angle, depending on factors including the in situ stress ratio. At this location, $\sigma_{1}$ would be, for example, inclined at approximately $25^{\circ}$ and the conjugate critical structures would be oriented at approximately $5^{\circ}$ into the slope and $55^{\circ}$ out of the slope. Movement on the low angle structures can be upward into the pit and may appear to be heave in the pit floor (Figure 10(c)). Movement on the high-angle structures can also appear to be heave in the pit floor (Figure 10(d)).
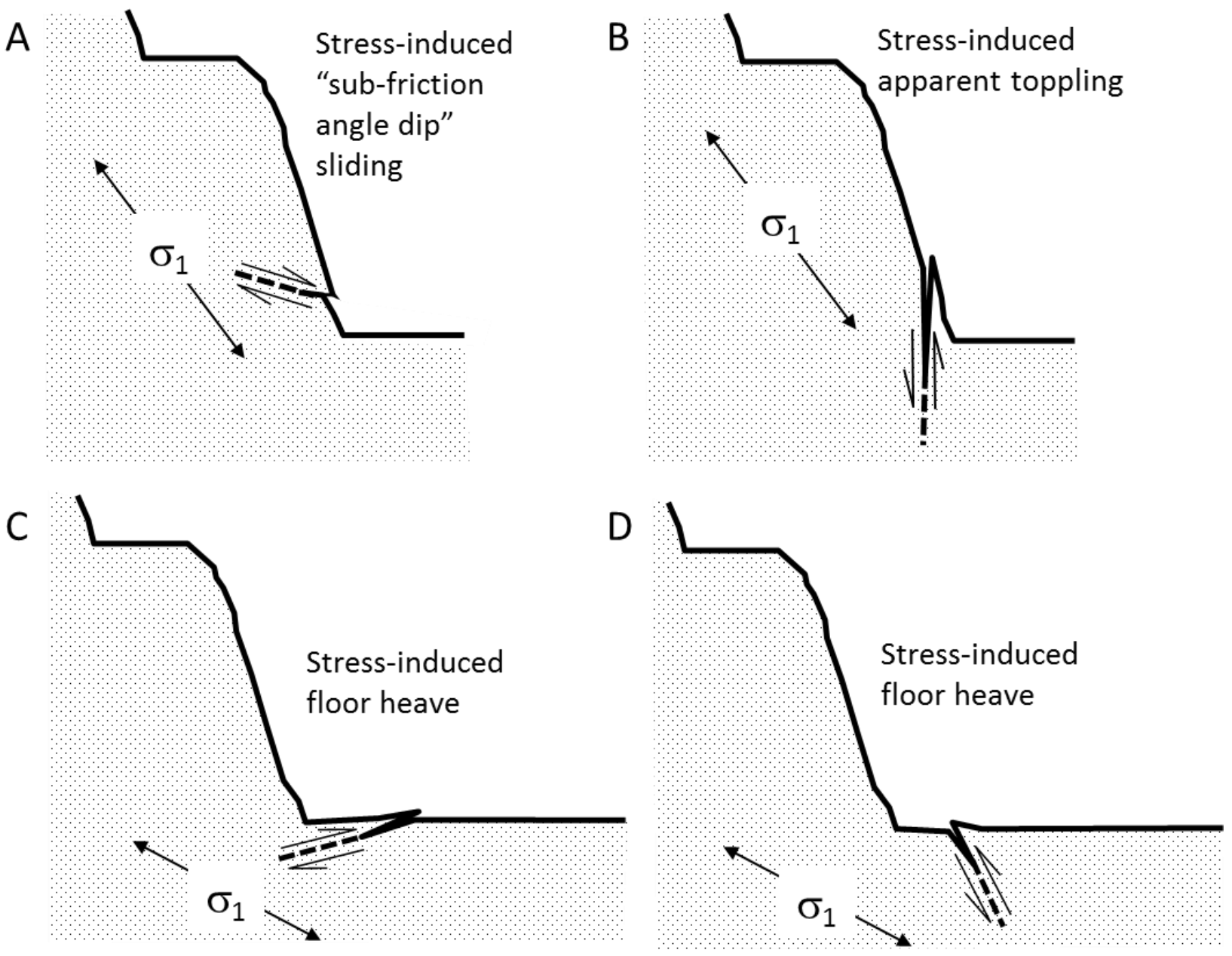

Figure 10 Schematic cross-sections showing examples of stress-induced movement on structures 
Notice that the type of structures illustrated in Figure 10 daylight at one end with the other end extending into the rock mass where the high stress effects have been applied. The structures are typically constrained from undergoing large displacements. The structures may initiate on-going structural unravelling or initiate failure of bridges constraining movement on other structures.

Structures with orientations favouring gravity-driven shear direction out of the slope (Figure 10(a) and (c)) may be more prone to becoming part of or initiating larger scale instability.

The angular relationships illustrated in Figure 10 are for shear zones with intermediate friction and dilatancy forming at $30^{\circ}$ to $\sigma_{1}$. More specifically, the shear structures may form at $45^{\circ}$ to $\sigma_{1}$ in the non-dilatant case (Figure $11(\mathrm{a})$ and (b)) or $15^{\circ}$ to $\sigma_{1}$ in the highly dilatant case (Figure $11(\mathrm{c})$ and (d)).

Rock slopes which contain structural weakness oriented in one or both of the local critical orientations will be expected to undergo plastic yield at a lower threshold than other rock masses. Since dilatancy is expected to form a peak at peak strength and reduce to some residual value in post-peak conditions, it is expected also that new shear structures formed at the peak strength of the rock mass will be most dilatant and therefore at lower angles to $\sigma_{1}$. Pre-existing weaknesses, in comparison, are expected to require less dilatancy than the formation of a new structure and therefore are expected to form at higher angles to $\sigma_{1}$.

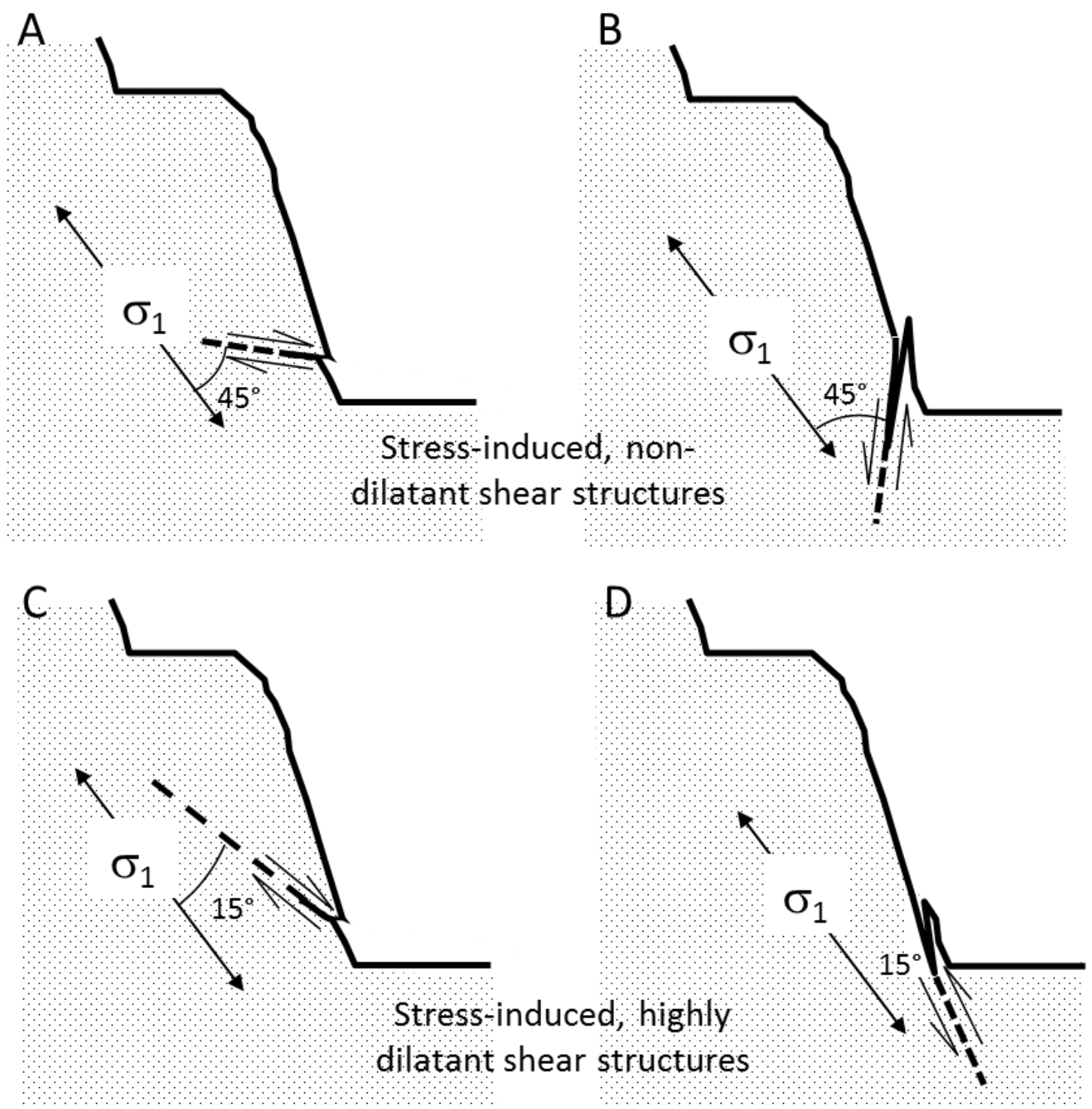

Figure 11 Schematic cross-sections showing examples of stress-induced movement on structures showing the range of orientations in relation to dilatancy; (a) and (b) examples of nondilatant orientations; (c) and (d) examples of highly dilatant orientations 


\section{$5 \quad$ Conclusions}

The orientation of localised shear structures is related to the dilatancy of the deformation at the time of their formation. This applies to the formation of new shear structures and to the activation of shear displacement on existing weakness zones. The orientation of the stress trajectory in a slope can be determined from numerical modelling and tends to follow the slope. The presence of structures with critical orientations at highly stressed parts of the slope can be assessed by simple stereographic screening methods.

\section{Acknowledgement}

General discussions on rock mass behaviour and modelling with former colleagues at Coffey Mining are appreciated.

\section{References}

Alejano, L.R. and Alonso, E. (2005) Considerations of the dilatancy angle in rocks and rock masses, International Journal of Rock Mechanics and Mining Sciences, Elsevier, Vol. 42, pp. 481-507.

Bésuelle, P., Desrues, J. and Raynaud, S. (2000) Experimental characterisation of the localisation phenomenon inside a Vosges sandstone in a triaxial cell, International Journal of Rock Mechanics and Mining Sciences, Elsevier, Vol. 37, pp. 1223-1237.

Brown, E.T. (2008) Estimating the Mechanical Properties of Rock Masses, in Proceedings First Southern Hemisphere International Rock Mechanics Symposium (SHIRMS), Y. Potvin, J. Carter, A. Dyskin and R. Jeffrey (eds), Vol. 1 - Mining and Civil, 16-19 September 2008, Perth, Australia, Australian Centre for Geomechanics, Perth, pp. 3-22.

Cundall, P., Carranza-Torrez, C. and Hart, R. (2003) A new constitutive model based on the Hoek-Brown criterion, in Proceedings $3 r d$ International FLAC Symposium, FLAC and Numerical Modelling in Geomechanics, R.K. Brummer, P.P. Andrieux, C. Detournay and R. Hart (eds), 21-24 October 2003, Sudbury, Canada, Balkema, Lisse, pp. 17-25.

Detournay, E. (1986) Elastoplastic model of a deep tunnel for a rock with variable dilatancy, Rock Mechanics and Rock Engineering, Springer, Vol. 19, pp. 99-108.

Durney, D.W. (1979) Dilation in shear zones and its influence on the development of en echelon fractures, in Proceedings International Conference on Shear Zones in Rocks, 15-17 May 1979, Barcelona, Spain, Abstracts, p. 30.

Franz, J., Cai, Y. and Hebblewhite, B. (2007) Numerical modelling of composite large scale rock slope failure mechanisms dominated by major geological structures, in Proceedings 11th Congress of the International Society of Rock Mechanics, L. Ribero e Sousa, C. Olalla and N.F. Grossman (eds), 9-13 July 2007, Lisbon, Portugal, Taylor \& Francis, Oxford, pp. 633-636.

Hoek, E. and Bray, J. (1981) Rock Slope Engineering, Taylor \& Francis, Oxford, p. 358.

Hoek, E. and Brown, E.T. (1997) Practical estimates of rock mass strength, International Journal of Rock Mechanics and Mining Sciences, Elsevier, Vol. 34, No. 8, pp. 1165-1186.

Jaeger, J.C., Cook, N.G.W. and Zimmerman, R.W. (2007) Fundamentals of Rock Mechanics, 4th edition, Blackwell Publishing, p. 22.

Jones, R.R. and Tanner, P.W.G. (1995) Strain partitioning in transpression zones, Journal of Structural Geology, Elsevier, Vol. 17, pp. 793-802.

Myrvang, A., Hansen, S.E. and Sorensen, T. (1993) Rock stress redistribution around an open pit mine in hardrock, International Journal of Rock Mechanics and Mining Sciences \& Geomechanics Abstracts, Vol. 30, pp. 1001-1004.

Rudnicki, J.W. and Rice, J.R. (1975) Conditions for the localization of deformation in pressure-sensitive dilatant materials, Journal of the Mechanics and Physics of Solids, Elsevier, Vol. 23, pp. 371-394.

Schopfer, M.P.J. and Childs, C. (2013) The orientation and dilatancy of shear bands in a bonded particle model for rock, International Journal of Rock Mechanics and Mining Sciences, Elsevier, Vol. 57, pp. 75-88.

Simmons, J.V. and Simpson, P.J. (2006) Composite failure mechanisms in coal measures' rock masses-myths and reality, The Journal of The South African Institute of Mining and Metallurgy, The South African Institute of Mining and Metallurgy, Vol. 106, pp. 459-469.

Smith, J.V. and Durney, D.W. (1992) Experimental formation of brittle structural assemblages in oblique divergence, Tectonophysics, Vol. 216, Elsevier, pp. 235-253.

Stacey, T.R., Xianbin, Y., Armstrong, R. and Keyter, G.J. (2003) New slope stability considerations for deep open pit mines, The Journal of the South African Institute of Mining and Metallurgy, The South African Institute of Mining and Metallurgy, Vol. 103, pp. 373-389.

Yu, H.S. (2006) Plasticity and Geotechnics, Springer, 522 p.

Yuan, S.C. and Harrison, J.P. (2004) An empirical dilatancy index for the dilatant deformation of rock, International Journal of Rock Mechanics and Mining Sciences, Elsevier, Vol. 41, pp. 679-686. 